\title{
Demonstration of the LUCA process for the separation of americium(III) from curium(III), californium(III), and lanthanides(III) in acidic solution using a synergistic mixture of bis(chlorophenyl)dithiophosphinic acid and tris(2-ethylhexyl)phosphate
}

\author{
By G. Modolo ${ }^{1, *}$, P. Kluxen ${ }^{1}$ and A. Geist ${ }^{2}$ \\ ${ }^{1}$ Forschungszentrum Jülich, Institute for Energy Research, Safety Research and Reactor Technology, 52425 Jülich, Germany \\ ${ }^{2}$ Forschungszentrum Karlsruhe GmbH, Institut für Nukleare Entsorgung, Postfach 3640, 76021 Karlsruhe, Germany
}

(Received December 11, 2008; accepted in revised form November 21, 2009)

\begin{abstract}
Minor actinides / Lanthanides / Americium / Curium / Partitioning / Solvent extraction / Centrifugal contactors / LUCA process
\end{abstract}

\begin{abstract}
Summary. The LUCA process was developed at Forschungszentrum Jülich for the selective separation of Am(III) from an acidic solution containing the trivalent actinides $\mathrm{Am}(\mathrm{III}), \mathrm{Cm}(\mathrm{III})$, and $\mathrm{Cf}(\mathrm{III})$ as well as lanthanides. A mixture of $0.4 \mathrm{~mol} / \mathrm{L}$ bis(chlorophenyl)dithiophosphinic acid and $0.15 \mathrm{~mol} / \mathrm{L}$ tris(2-ethylhexyl)phosphate dissolved in $20 \%$ isooctane $/ 80 \%$ tert-butyl benzene was used as the extractant. The process was carried out in centrifugal contactors using an optimized flowsheet involving 7 stages for extraction, 9 stages for scrubbing and 8 stages for back-extraction. Very encouraging results were obtained. A high feed decontamination factor was obtained for $\mathrm{Am}(\mathrm{III})$ ( $>1000)$, and recovery in the product after stripping was higher than $99.8 \%$. The Am(III) product was contaminated with $0.47 \% \mathrm{Cm}$ (III). More than $99.9 \% \mathrm{Cf}(\mathrm{III}), \mathrm{Eu}(\mathrm{III})$ and $>99.5 \% \mathrm{Cm}(\mathrm{III})$ inventories were directed to the raffinate and the contamination with Am(III) $(<0.08 \%)$ was low. The experimental results were in good agreement with the predictions of a computer code.
\end{abstract}

\section{Introduction}

Plutonium and the minor actinides (MA) Np, Am and Cm are mainly responsible for the long-term radiotoxicity of the waste generated from nuclear power production. If these radionuclides are removed from the waste (partitioning) and converted by neutron fission (transmutation) into shorterlived or stable elements, the remaining waste loses most of its long-term radiotoxicity. Thus, partitioning and transmutation are considered attractive options for reducing the burden on geological disposals. This is important both in the case of a nuclear phase-out, as well in the case of the continuous use of nuclear power as part of a sustainable energy supply [1]. Today, Pu and uranium are industrially separated

\footnotetext{
*Author for correspondence (E-mail: g.modolo@fz-juelich.de).
}

from spent fuel using the well-established PUREX process, which can also be adapted for partitioning $\mathrm{Np}$ [2]. There is no potential for recovering Am or $\mathrm{Cm}$ using the PUREX process because the tri-n-butylphosphate (TBP) extractant shows a very low affinity for trivalent actinides. During the last decade a large amount of research has been conducted in several countries on the separation and recovery of Am and $\mathrm{Cm}$ from the high-level liquid waste (HLLW) fraction of the PUREX process. A comprehensive survey on actinide separation science and technology is given by Nash et al. [3]. Most partitioning strategies rely on the following separation processes.

1. Separation of uranium and/or plutonium from spent fuel dissolution liquors (e.g. PUREX, UREX).

2. Co-extraction of the trivalent actinides and lanthanides (e.g. TRUEX, DIAMEX, TRPO, TODGA).

3. Separation of trivalent actinides from lanthanides (e.g. TALSPEAK, SANEX).

The last step is important because it is essential to separate americium and curium from trivalent lanthanides to avoid the strong absorption of thermalized neutrons by the lanthanides, particularly if the trivalent actinides are to be recycled as fuel (or targets for transmutation) in a current generation reactor. Due to similarities in the chemical properties and behaviour of trivalent actinides and lanthanides extractants or complexing agents containing soft donor atoms such as $\mathrm{N}, \mathrm{S}, \mathrm{Cl}$, etc. are required for reliable group separations [4-8]. After the An(III)/Ln(III) separation process, the product fraction contains approx. 0.35 to $0.45 \mathrm{~g} / \mathrm{L} \mathrm{Am}$ and Cm (e.g. after a BTBP process [9]).

In principal, both elements could be transmuted together in a fast reactor or ADS system. However, because of the high heat decay and neutron emission of curium, any dry or wet fabrication process will require remote handling and continuous cooling in hot cells behind thick concrete shielding. The development of a simple, compact and robust fabrication process appears to be a great challenge [10]. One option involves the interim storage of curium for about 
100 years, after which the relatively short-lived curium isotopes $\left({ }^{242} \mathrm{Cm},{ }^{243} \mathrm{Cm}\right.$, and $\left.{ }^{244} \mathrm{Cm}\right)$ decay to form plutonium isotopes which can then be easily separated from americium. Therefore, an effective method for separating $\mathrm{Am}$ from $\mathrm{Cm}$ prior to re-fabrication is a major prerequisite for the discussion of further fuel cycle scenarios [1].

The separation of adjacent trivalent actinides represents an even more challenging task than the $\mathrm{An}(\mathrm{III}) / \mathrm{Ln}$ (III) separation. It is known that the separation of americium from curium is a very difficult operation, due to the very similar properties of these elements [3]. The development of solid ion-exchange materials, which are capable of capturing and reversibly releasing the metal ions back into the contacting solution, represents a big step forward in separating elements with similar properties. These separations depend more on differences in the complexing power of the eluants towards the metal ions than on the selectivity of the resin. According to this method, $\mathrm{Am} / \mathrm{Cm}$ separation is carried out by selective elution of $\mathrm{Am}$ (III) and $\mathrm{Cm}$ (III), and the quality of separation is a function of the nature of the eluant. Promising results for transplutonium separations were obtained on a DOWEX 50 cation exchanger using $\alpha$-hydroxy-isobutyric acid as an eluant [11]. The $\alpha$-hydroxy-isobutyric acid provides average separation factors for adjacent lanthanides or trivalent actinides of about 1.3-1.5.

Numerous other techniques, including high-pressure ion exchange, extraction chromatography, and solvent extraction using e.g. di(2-ethylhexyl)phosphoric acid (HDEHP) have also been used for $\mathrm{Am}(\mathrm{III}) / \mathrm{Cm}$ (III) separation and purification [12-15]. However, the $\mathrm{Am} / \mathrm{Cm}$ separation factors were low and do not exceed 3, necessitating a large number of stages in order to obtain a pure product. The TALSPEAK process can be adapted for liquid membrane separations [16]. The authors report on the use of a "supported liquid membrane" impregnated with HDEHP for the separation of $\mathrm{Am}$ (III) and $\mathrm{Cm}$ (III) using DTPA, citric acid, and the potassium salt of a heteropolyacid, potassium phosphotungstate $\left(\mathrm{K}_{10} \mathrm{P}_{2} \mathrm{~W}_{17} \mathrm{O}_{61}\right)$, as aqueous complexants. The optimum separation factors reported are $\mathrm{SF}_{\mathrm{Am}(\mathrm{III}) / \mathrm{Cm} \text { (III) }} \approx 5.0$.

The best separation of transplutonium elements has been obtained using methods based on the various oxidation states of the separated elements. Contrary to $\mathrm{Cm}$, Am can be oxidized in aqueous solutions to oxidation states higher than III, i.e. IV, V and VI. Nevertheless, these Am oxidation states are thermodynamically unstable in acidic aqueous solutions [17]. The solvent extraction of hexavalent Am has been studied by several authors $[18,19]$. In the SESAME process, developed at CEA (France), an electrochemical method was used to oxidize the americium to IV and VI in the presence of heteropolyanions, such as phosphotungstate $\mathrm{P}_{2} \mathrm{~W}_{17} \mathrm{O}_{61}{ }^{10-}$. The $\mathrm{Am}(\mathrm{VI})$ generated in this manner can be separated from $\mathrm{Cm}$ (III) by extraction, for example with TBP. In-depth experience has been gained at CEA over the last 20 years, and several SESAME tests have been carried out in Marcoule, France [20]. Although the results of the tests were encouraging, the process was nevertheless not sufficiently robust for further industrialisation.

The CEA is now considering the development of a novel option for $\mathrm{Am} / \mathrm{Cm}$ separation based on the difference of the affinity of the DIAMEX extractant (DMDOHEMA) for $\mathrm{Am}$ (III) and $\mathrm{Cm}$ (III) [21]. Since the Am(III)/Cm(III) sep- aration factor of 1.6 is low, this process requires a large number of stages. Nevertheless, a flowsheet comprising 24 extraction, 24 scrubbing and 8 stripping stages was successfully tested in 2002 using surrogate solutions without significant difficulties. The performance of this test was good, as was predicted by calculations: more than $99.9 \%$ of each actinide was recovered. $0.6 \% \mathrm{Am}$ was found within the $\mathrm{Cm}$ product solution, $0.7 \% \mathrm{Cm}$ within $\mathrm{Am}$ product solution, and only $0.02 \% \mathrm{Am}$ and $0.01 \% \mathrm{Cm}$ remained in the stripped solvent.

Recently, Myasoedov et al. [22] reported on Am(III)/ $\mathrm{Cm}$ (III) separation by counter-current chromatography (CCC) using the DIAMEX solvent. The application of CCC, a multistage extraction technique, makes it possible to separate the elements within $100 \mathrm{~min}$ : the $\mathrm{Cm}$ fraction contains 99.5\% $\mathrm{Cm}(\mathrm{III})$ and $0.6 \% \mathrm{Am}(\mathrm{III})$ inventories and the $\mathrm{Am}$ fraction contains $99.4 \% \mathrm{Am}(\mathrm{III})$ and $0.5 \% \mathrm{Cm}$. However, CCC can only be applied to analytical and radiochemical separations on a laboratory scale, whereas solvent extraction processes are predominantly proposed for use on an industrial scale.

The synergistic mixture (Fig. 1) composed of bis(chlorophenyl)dithiophosphinic acid $\left[(\mathrm{ClPh})_{2} \mathrm{PSSH}\right]$ and tris(2ethylhexyl)phosphate (TEHP) showed a very high affinity for actinides(III) over lanthanides(III). Am(III)/Eu(III) separation factors were over 2000. Surprisingly high Am(III)/ $\mathrm{Cm}$ (III) separation factors of $6-10$ were also reported by Modolo et al. [23]. Using ${ }^{1} \mathrm{H}-\mathrm{NMR}$, the aggregation of $(\mathrm{ClPh})_{2} \mathrm{PSSH}$ has been determined, and its effect on the extraction has been considered. Treatment of distribution data by slope analysis suggests that the extracted $\mathrm{An}(\mathrm{III})$ and $\mathrm{Ln}(\mathrm{III})$ complexes have the composition of $\mathrm{ML}_{3}(\mathrm{Syn})_{\mathrm{xorg}}$, where $\mathrm{HL}=(\mathrm{ClPh})_{2} \mathrm{PSSH}$ and $\mathrm{Syn}=$ neutral synergist TEHP. Furthermore, the thermodynamic parameters $\Delta H^{0}$, $\Delta S^{0}$, and $\Delta G^{0}$ of the extraction have been determined in the temperature range between 10 and $45^{\circ} \mathrm{C}$.

Based on the extraordinary extraction properties of the above synergistic mixture, the LUCA process [24] was invented. LUCA is the acronym for Lanthaniden Und Curium Americum Trennung. The present paper relates to the development and demonstration of a continuous LUCA process for the selective recovery of Am(III) from an aqueous nitric acid solution $\left(\approx 0.1 \mathrm{~mol} / \mathrm{L} \mathrm{HNO}_{3}\right)$ containing trivalent actinides (i.e. $\mathrm{Am}(\mathrm{III}), \mathrm{Cm}(\mathrm{III})$ and $\mathrm{Cf}(\mathrm{III})$ ) and trivalent lanthanides.

A detailed stability study of the $(\mathrm{ClPh})_{2} \mathrm{PSSH}$ used in the LUCA process was carried out previously [25]. The experimental investigations revealed that aromatic dithiophos-<smiles>S=P(S)(c1ccc(Cl)cc1)c1ccc(Cl)cc1</smiles>

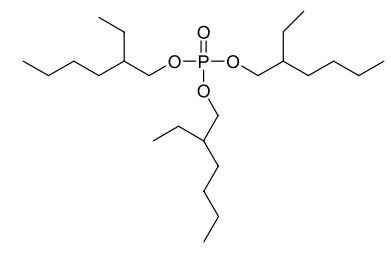

$(\mathrm{ClPh})_{2} \mathrm{PSSH}$

$+$

TEHP

Fig. 1. Synergistic mixture of bis(chlorophenyl)dithiophosphinic acid and tris(2-ethylhexyl)phosphate used in the LUCA process. 
phinic acids are more stable to hydrolysis and radiolysis than aliphatic dithiophosphinic acids (Cyanex 301). The aromatic dithiophosphinic acids dissolved in an aromatic solvent such as toluene do not degrade in contact with $3 \mathrm{~mol} / \mathrm{L} \mathrm{HCl}$, degrade only slightly with $3 \mathrm{~mol} / \mathrm{L} \mathrm{H}_{2} \mathrm{SO}_{4}$ but completely in contact with $>2 \mathrm{~mol} / \mathrm{L} \mathrm{HNO}_{3}$ during $100 \mathrm{~d}$ of contact. With the aid of the $\mathrm{HNO}_{2}$ scavengers amidosulfuric acid, hydrazine or urea it was possible to also stabilize the extractants in contact with $2 \mathrm{M} \mathrm{HNO}_{3}$ against hydrolysis.

It has been found that the hydrolytic and radiolytic degradation by oxidation of the dithiophosphinic acids produces the corresponding monothioderivatives and also the dioxophosphinic acids which appear to have no significant influence on extraction. The distribution ratio $D_{\mathrm{Am}}$ and, consequently, the e.g. Am/Eu separation factors decrease with increasing degradation but this decrease can be explained by the reduction in extractant concentration. The possible radiolytic degradation of TEHP and the effect on extraction has so far not been investigated and taken into account within the framework of this study. However, it can be supposed that TEHP shows similar stability as for TBP. For the required regeneration, however, methods still have to be developed to separate the oxidation products formed during hydrolysis and radiolysis. This will by the subject of future investigations.

Within the present study optimisation studies were carried out to define the best conditions for extraction, scrubbing and stripping. In addition to the batch extraction studies, a single-stage extraction experiment was conducted to obtain more data on the system kinetics, and to generate data required for the flowsheet calculations. After the data was collected, a 24-stage flowsheet was designed, and the final assessment was performed in a counter-current test using miniature centrifugal contactors.

\section{Experimental}

\subsection{Reagents}

$(\mathrm{ClPh})_{2} \mathrm{PSSH}$ was synthesized in our own laboratories according to the method [8] previously described, and purified by recrystallization (twice from isopropyl alcohol). TEHP (Aldrich, 97\%) was used as received without further purification. Tert-butyl benzene (Merck, p. a.) and isooctane (Merck, p.a.) were used as the organic diluent. The organic solution was prepared by dissolving $0.4 \mathrm{~mol} / \mathrm{L}(\mathrm{ClPh})_{2} \mathrm{PSSH}$ and $0.15 \mathrm{~mol} / \mathrm{L} \mathrm{TEHP}$ in a tertbutyl benzene/isooctane (80/20) mixture. This solvent composition was elaborated according to the published data in reference [23] and further unpublished optimisation studies. Addition of $20 \%$ isooctane increases slightly the actinides(III) distribution ratios, whereas $\mathrm{Am}(\mathrm{III}) / \mathrm{Cm}(\mathrm{III})$ separation factor was not affected.

All other reagents and chemicals were of analytical reagent grade. Nitric acid solutions were prepared by diluting concentrated nitric acid (Merck, p. a.) with ultrapure water. The radiotracers ${ }^{241} \mathrm{Am},{ }^{244} \mathrm{Cm},{ }^{252} \mathrm{Cf}$, and ${ }^{152} \mathrm{Eu}$ were supplied by Isotopendienst M. Blaseg $\mathrm{GmbH}$, Waldburg, Germany. The composition of the LUCA feed used for the single-centrifuge and full counter-current test is shown in Table 1.

\subsection{Analysis}

Activity measurements of the $\gamma$-ray emitters ${ }^{241} \mathrm{Am}$ and ${ }^{152} \mathrm{Eu}$ were performed with a HPGe $\gamma$-ray spectrometer, EG-G Ortec, Munich, Germany. The nuclides ${ }^{244} \mathrm{Cm},{ }^{241} \mathrm{Am}$ and ${ }^{252} \mathrm{Cf}$ were measured by means of $\alpha$-spectrometry, EG-G Ortec. The acidity of aqueous solutions was determined by potentiometric titration, using a Metrohm 798 MPT Titrino device and $\mathrm{a}[\mathrm{NaOH}]=0.1 \mathrm{~mol} / \mathrm{L}$ or $0.01 \mathrm{~mol} / \mathrm{L}$ solution.

\subsection{Equipment and procedure}

\subsubsection{Batch extraction tests}

The batch extraction experiments were performed in $2 \mathrm{~mL}$ glass vials. $500 \mu \mathrm{L}$ organic and aqueous phases were spiked with $10 \mu \mathrm{L}$ radioactive tracer solution and equilibrated for $15 \mathrm{~min}$ by vigorous shaking in a vortex mixer. This contact time was sufficient to attain the distribution equilibrium. After phase separation by centrifugation, $200 \mu \mathrm{L}$ aliquots of each phase were withdrawn for radio analysis.

\subsubsection{Single-centrifuge experiments}

The experiments were performed in a single-stage centrifugal contactor setup, comprising a single $1 \mathrm{~cm}$ stainless steel centrifugal contactor (produced by INET, China) and a contactor house, which was a self-produced Plexiglas copy of the original. Two syringe pumps were connected to the contactor and used to precisely pump the organic and aqueous solutions after prior calibration. The experimental conditions for the determination of the centrifuge efficiency during extraction, scrubbing and stripping are summarized in Table 2.

First, the extraction performance was tested. Attainment of the steady state (after $\approx 30$ min operation) was checked by $\gamma$-spectrometry of ${ }^{241} \mathrm{Am}$ and ${ }^{152} \mathrm{Eu}$. After extraction, the collected organic solution was used for scrubbing with $0.23 \mathrm{~mol} / \mathrm{L} \mathrm{HNO}_{3}+0.5 \mathrm{~mol} / \mathrm{L} \mathrm{NaNO}_{3}$. Stripping was carried out with $0.7 \mathrm{~mol} / \mathrm{L} \mathrm{HNO}_{3}$ using the collected organic solution after scrubbing. After each step, distribution ratios were also determined using the solutions taken from the wells after the contactor was completely emptied. Additional batch tests were performed in glass vials to achieve the equilibrium data: $3 \mathrm{~mL}$ solvent were contacted for $15 \mathrm{~min}$ with $3 \mathrm{~mL}$ feed ( $c f$. Table 1). Phases were separated by centrifugation and samples were taken for analysis. $1 \mathrm{~mL}$ loaded organic phase from the extraction was used for scrubbing ( $15 \mathrm{~min}$ ) with $0.23 \mathrm{~mol} / \mathrm{L} \mathrm{HNO}_{3}+0.5 \mathrm{~mol} / \mathrm{L} \mathrm{NaNO}_{3}$.

Table 1. Composition of the synthetic An(III)/Ln(III) feed used for the single-centrifuge tests and the full counter-current test.

\begin{tabular}{ll}
\hline Solute & Concentration \\
\hline${ }^{241} \mathrm{Am}$ & $2.89 \mathrm{MBq} / \mathrm{L}$ \\
${ }^{244} \mathrm{Cm}$ & $2.79 \mathrm{MBq} / \mathrm{L}$ \\
${ }^{252} \mathrm{Cf}$ & $1.75 \mathrm{MBq} / \mathrm{L}$ \\
${ }^{152} \mathrm{Eu}$ & $5.20 \mathrm{MBq} / \mathrm{L}$ \\
$\mathrm{HNO}_{3}$ & $0.13 \mathrm{or} 0.084 \mathrm{~mol} / \mathrm{L}$ \\
$\mathrm{NaNO}_{3}$ & $0.5 \mathrm{~mol} / \mathrm{L}$ \\
$\mathrm{Eu}^{2}$ & $100 \mathrm{mg} / \mathrm{L}$ \\
\hline
\end{tabular}


Table 2. Conditions for the determination of the extraction, scrubbing and stripping efficiency of a single centrifuge.

\begin{tabular}{|c|c|c|c|}
\hline Conditions & Organic phase & Aqueous phase & $\mathrm{A} / \mathrm{O}$ ratio \\
\hline Extraction & $\begin{array}{l}0.4 \mathrm{~mol} / \mathrm{L}(\mathrm{ClPh})_{2} \mathrm{PSSH}+ \\
0.15 \mathrm{~mol} / \mathrm{L} \mathrm{TEHP} \mathrm{in} \\
20 \% \text { isooctane } / 80 \% \text { tert- } \\
\text { butyl benzene }\end{array}$ & $\begin{array}{l}c f \text {. Table } 1 \\
0.13 \mathrm{~mol} / \mathrm{L} \mathrm{HNO}_{3}\end{array}$ & $\begin{array}{l}35 \mathrm{~mL} / \mathrm{h} / 25 \mathrm{~mL} / \mathrm{h} \\
50 \mathrm{~mL} / \mathrm{h} / 35 \mathrm{~mL} / \mathrm{h} \\
70 \mathrm{~mL} / \mathrm{h} / 50 \mathrm{~mL} / \mathrm{h}\end{array}$ \\
\hline Scrubbing & $\begin{array}{l}\text { Loaded organic phase collected } \\
\text { from extraction }\end{array}$ & $\begin{array}{l}0.23 \mathrm{~mol} / \mathrm{L} \mathrm{HNO}_{3}+ \\
0.5 \mathrm{~mol} / \mathrm{L} \mathrm{NaNO}_{3}\end{array}$ & $\begin{array}{l}10 \mathrm{~mL} / \mathrm{h} / 25 \mathrm{~mL} / \mathrm{h} \\
15 \mathrm{~mL} / \mathrm{h} / 35 \mathrm{~mL} / \mathrm{h} \\
20 \mathrm{~mL} / \mathrm{h} / 50 \mathrm{~mL} / \mathrm{h}\end{array}$ \\
\hline Stripping & $\begin{array}{l}\text { Loaded organic phase collected } \\
\text { from scrubbing }\end{array}$ & $0.7 \mathrm{~mol} / \mathrm{L} \mathrm{HNO}_{3}$ & $\begin{array}{l}25 \mathrm{~mL} / \mathrm{h} / 25 \mathrm{~mL} / \mathrm{h} \\
35 \mathrm{~mL} / \mathrm{h} / 35 \mathrm{~mL} / \mathrm{h} \\
50 \mathrm{~mL} / \mathrm{h} / 50 \mathrm{~mL} / \mathrm{h}\end{array}$ \\
\hline
\end{tabular}

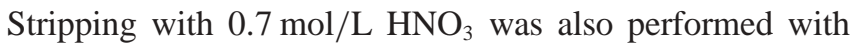
the loaded organic solution from extraction. Phase separation and analysis were performed as described above.

\subsection{Flowsheet design}

The flowsheet proposed for the separation test is shown in Fig. 2. It was calculated as described in the following. To calculate a flowsheet, a computer code similar to codes used for mass transfer calculations in hollow fibre modules [26,27] was established, however using discrete stages representing the centrifugal contactors used in the experimental setup. The code uses the equilibrium data shown in Fig. 3. A mean Am(III)/Cm(III) separation factor of 7 was used. Furthermore the code only takes into account diffusive mass transfer resistance, as mass transfer kinetics for a similar extraction system is controlled by diffusion [28].

To calculate fluxes in an extraction system controlled by diffusion, knowledge of the specific interfacial area (i.e.,

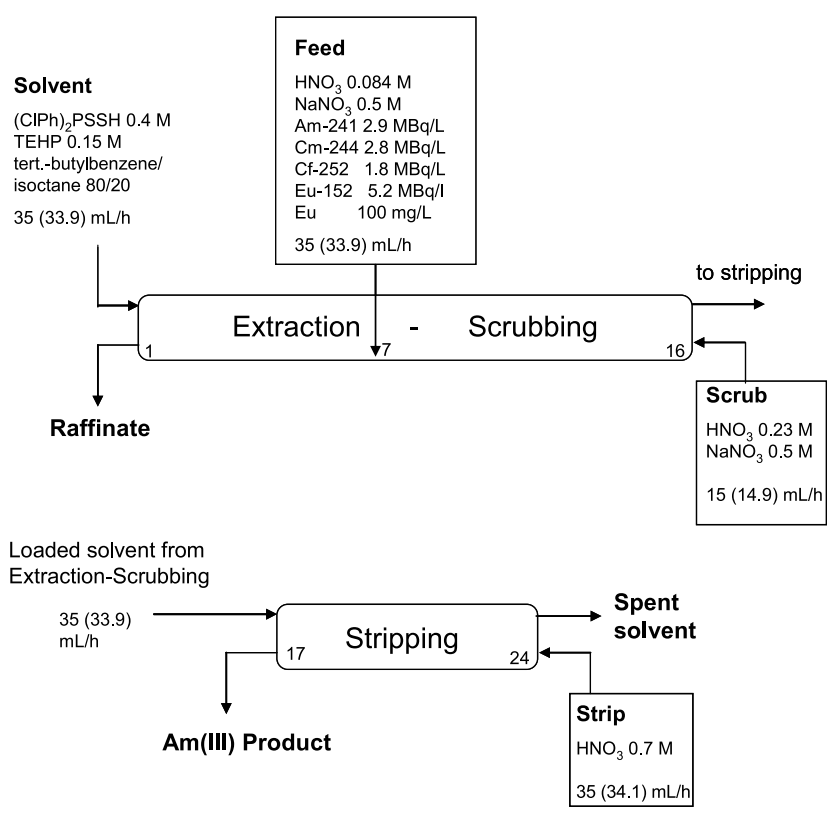

Fig. 2. Flowsheet for the LUCA process with proposed and actually measured (in brackets) flow rates. droplet size and holdup) and of mass transfer coefficients is required. As these are not easily accessible for a centrifugal contactor, we assumed reasonable individual mass transfer coefficients for all species involved, and used the drop size as fitting parameter: To describe the efficiency of the centrifuges under extraction, scrubbing and stripping conditions, a single-stage computer code was used, and drop sizes were adjusted to give the non-equilibrium distribution ratios found for the conditions of the experimental singlestage runs (see Table 2). The fit drop sizes were not varied with flow rate (work performed by Leonard, e.g. [29], indicates that this is a realistic assumption). The fit drop sizes were the same for the scrubbing and stripping sections; the fit drop size in the extraction section was $35 \%$ of that used in the scrubbing and stripping sections. However, these drop sizes used in the calculations do not necessarily represent the actual conditions in the mixing zone of the centrifugal contactors (the single-stage calculations could also be fit by using constant drop sizes throughout and varying the mass transfer coefficients).

The fit drop sizes were then used in the multi-stage counter-current code to calculate a flowsheet. The calculations aimed achieving $\approx 0.1 \% \mathrm{Am}(\mathrm{III})$ in the raffinate and $\approx 2 \% \mathrm{Cm}$ (III) in the product (of course, the product is even better decontaminated from metal ions less-extracted than $\mathrm{Cm}(\mathrm{III})$, i.e. $\mathrm{Cf}(\mathrm{III})$ and $\mathrm{Eu}(\mathrm{III})$, which is the reason why they were not included in the calculations). The major constraint was that 16 stages were available for extraction and scrubbing. Of the 16 stages available, seven stages were dedicated to extraction and nine stages to scrubbing. Eight stages were used for stripping. After the test was performed, the flowsheet was re-calculated with the flow rates and nitric acid concentrations that were actually measured.

\subsubsection{Counter-current test in miniature centrifugal contactor battery}

The continuous extraction/scrubbing and stripping tests with an actinide(III)/lanthanide(III) surrogate were carried out using Chinese $1 \mathrm{~cm}$ miniature centrifugal extractors in a counter-current mode. Details of the contactor setup can be found elsewhere [30]. The proposed flow rates ( $c f$. Fig. 2) were adjusted before the tests were started using 
calibrated metering pumps with associated controllers. During the tests, the actual volumetric flow rates were recorded by a mass balance. Since only 16 stages were available, stripping was performed on the second day. The solvent loaded with Am(III) (coming from stage 16) was collected in two batches for this purpose and the steady-state fraction was used for stripping. The attainment of the steady state was checked using gamma spectrometric measurements of ${ }^{241} \mathrm{Am}$ and ${ }^{152} \mathrm{Eu}$ and by alpha spectrometry of ${ }^{241} \mathrm{Am}$ and ${ }^{244} \mathrm{Cm}$ at the outlets of raffinate, collected solvent (at stage 16), Am(III) product (at stage 17) and stripped solvent. At the end of the experiments, the motors and pumps were switched off and the individual stages were drained. Subsequently, the organic phases were separated from the aqueous phases by centrifuging, and aliquots from both phases were used for the analyses. The following analyses were carried out on all samples collected from all stages (aqueous and organic), including the samples taken to determine the transient state: $\gamma$-spectroscopy for ${ }^{241} \mathrm{Am},{ }^{152} \mathrm{Eu}$ and $\alpha$-spectroscopy for ${ }^{241} \mathrm{Am},{ }^{244} \mathrm{Cm}$ and ${ }^{252} \mathrm{Cf}$. The acidity profile was determined for the aqueous phase by titration with $\mathrm{NaOH}$.

\section{Results and discussion}

\subsection{Optimisation studies for $\mathrm{Am}$ (III)/Cm(III) separation}

The primary aim of the present studies was to determine the conditions for continuous $\mathrm{Am}$ (III)/Cm(III) separation with the aid of centrifugal extractors. Batch studies with $\mathrm{HNO}_{3}$ solutions spiked with ${ }^{241} \mathrm{Am}$ and ${ }^{244} \mathrm{Cm}(\approx 1000 \mathrm{~Bq} / \mathrm{mL}$ each) showed, however, that the aqueous phase emulsified after extraction at $\mathrm{HNO}_{3}$ concentrations $<0.2 \mathrm{~mol} / \mathrm{L}$. This was not caused by degradation of the solvent and was not observed with feeds containing macro amounts of lanthanides. In further investigations, we found that this problem did not occur when the aqueous feed phase contained a salt load (e.g. lanthanide nitrates, sodium nitrate, or $\mathrm{HNO}_{3}>$
$0.2 \mathrm{~mol} / \mathrm{L}$ ). For the optimisation studies, we therefore used nitric acid solutions $(0.01-0.5 \mathrm{~mol} / \mathrm{L})$ containing variable $\mathrm{NaNO}_{3}$ concentrations $(0.25,0.5$ and $1.0 \mathrm{~mol} / \mathrm{L})$ in order to improve the hydrodynamic properties. Fig. 3 shows the results of $\mathrm{Am}(\mathrm{III})$ and $\mathrm{Cm}$ (III) extractions (both present in the same vial) from 0.05 to $0.5 \mathrm{~mol} / \mathrm{L} \mathrm{HNO}_{3}$ for varied $\mathrm{NaNO}_{3}$ concentrations. We observed a faster phase separation with rising $\mathrm{NaNO}_{3}$ concentrations, while $\mathrm{Am}$ (III) and $\mathrm{Cm}$ (III) distribution ratios decreased slightly for constant $\mathrm{HNO}_{3}$ concentration. $\mathrm{Am}$ (III) and $\mathrm{Cm}$ (III) distribution ratios determined by various methods ( $\gamma$-spectroscopy for ${ }^{241} \mathrm{Am}$; $\alpha$-spectroscopy for ${ }^{241} \mathrm{Am}$ and ${ }^{244} \mathrm{Cm}$; LSC for ${ }^{244} \mathrm{Cm}$ alone) showed good agreement.

\subsection{Single-centrifuge experiments}

Equilibrium batch extraction data are generally used to design flowsheets. To get an idea of how efficient each step (extraction, scrubbing and stripping) is, a series of singlecentrifuge experiments was also carried out. The results from single-centrifuge experiments at the flow rates proposed for the counter-current test, and the comparison with the computer code calculations and experimental batch equilibrium data are shown in Table 3. The flow rates used allow a residence time in the mixer of the centrifuges which is not sufficient to attain equilibrium: single-stage distribution ratios are lower (extraction) or higher (scrubbing and stripping) than the respective equilibrium distribution ratios.

The single-stage calculations were fit to the experimental data to agree with $\mathrm{Am}$ (III) distribution ratios for extraction and stripping and with $\mathrm{Cm}$ (III) distribution ratio for scrubbing. The reason for doing so is as follows: in the flowsheet calculations, only the Am(III) extraction section concentration profiles and the $\mathrm{Cm}$ (III) scrubbing section concentration profiles are sensitive to the drop size in the respective sections (the $\mathrm{Cm}$ (III) extraction section and Am(III) scrubbing section profiles are not sensitive). With regard to the stripping section, $\mathrm{Cm}$ (III) is stripped better than Am(III). Fitting

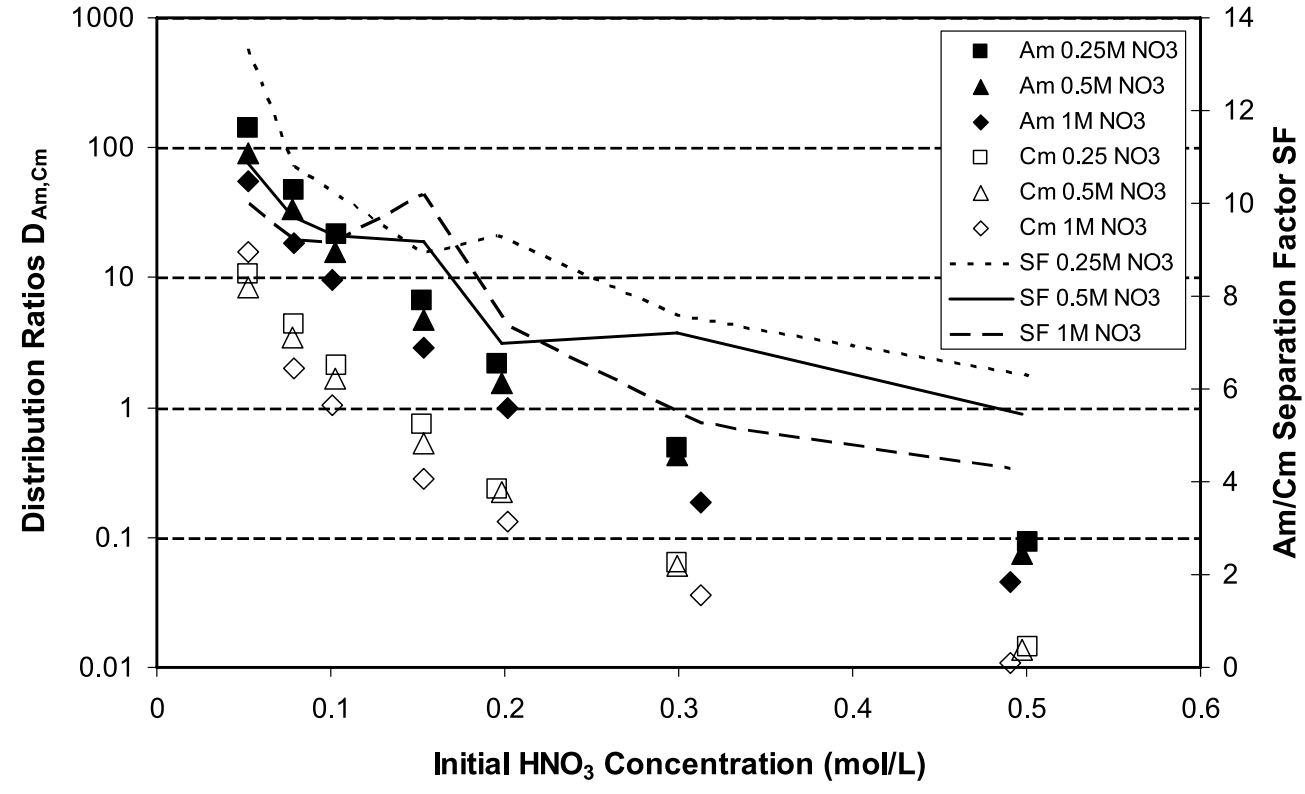

Fig. 3. Influence of $\mathrm{NaNO}_{3}$ on the extraction of $\mathrm{Am}(\mathrm{III})$ and $\mathrm{Cm}$ (III) from $\mathrm{HNO}_{3}$. Organic phase, $0.4 \mathrm{~mol} / \mathrm{L}(\mathrm{ClPh})_{2} \mathrm{PSSH}+$ $0.15 \mathrm{~mol} / \mathrm{L}$ TEHP in $20 \%$ isooctane/tert-butyl benzene. Aqueous phase, variable $\mathrm{HNO}_{3}+$ variable $\mathrm{NaNO}_{3}(0.25,0.5$ and $1 \mathrm{~mol} / \mathrm{L})$, trace amounts of ${ }^{241} \mathrm{Am}$, ${ }^{244} \mathrm{Cm}$. 
Table 3. Results of the experimental single centrifugal contactor tests and the comparison with single-stage calculations and batch extraction tests.

\begin{tabular}{|c|c|c|c|c|c|c|c|c|}
\hline Single centrifuge & $\mathrm{A} / \mathrm{O}$ ratio & $D_{\mathrm{Am}, \gamma}$ & $D_{\mathrm{Eu}, \gamma}$ & $D_{\mathrm{Am}, \alpha}$ & $D_{\mathrm{Cm}, \alpha}$ & $D_{\mathrm{Cf}, \alpha}$ & $\mathrm{SF}_{\mathrm{Am} / \mathrm{Cm}, \alpha}$ & $\mathrm{SF}_{\mathrm{Am} / \mathrm{Eu}, \gamma}$ \\
\hline Extraction & $50 / 35$ & 3.44 & 0.007 & 3.73 & 0.86 & 0.57 & 4.3 & 460 \\
\hline Calculation & & 3.48 & & 3.48 & 0.72 & & 4.8 & \\
\hline Batch/well & & 4.26 & 0.008 & 4.28 & 0.77 & 0.65 & 5.5 & 520 \\
\hline Scrubbing & $15 / 35$ & 2.66 & 0.063 & 3.08 & 0.60 & 0.58 & 5.1 & 42 \\
\hline Calculation & & 1.76 & & 1.76 & 0.57 & & 3.1 & \\
\hline Batch/well & & 0.84 & 0.015 & 1.17 & 0.22 & 0.30 & 5.4 & 54 \\
\hline Stripping & $35 / 35$ & 0.58 & 0.081 & 0.66 & 0.22 & 0.20 & 3.0 & 7 \\
\hline Calculation & & 0.56 & & 0.56 & 0.52 & & 1.1 & \\
\hline Batch/well & & 0.038 & 0.004 & 0.04 & 0.022 & 0.025 & 1.8 & 10 \\
\hline Batch tests & Mixing & $D_{\mathrm{Am}, \gamma}$ & $D_{\mathrm{Eu}, \gamma}$ & $D_{\mathrm{Am}, \alpha}$ & $D_{\mathrm{Cm}, \alpha}$ & $D_{\mathrm{Cf}, \alpha}$ & $\mathrm{SF}_{\mathrm{Am} / \mathrm{Cm}, \alpha}$ & $\mathrm{SF}_{\mathrm{Am} / \mathrm{Eu}, \gamma}$ \\
\hline Extraction & $15 \mathrm{~min}$ & 4.64 & 0.007 & 4.60 & 0.63 & 0.52 & 7.3 & 637 \\
\hline Scrubbing & $15 \mathrm{~min}$ & 1.09 & 0.32 & 1.24 & 0.22 & 0.34 & 5.7 & 3 \\
\hline Stripping & $15 \mathrm{~min}$ & 0.045 & - & 0.047 & 0.020 & 0.016 & 2.4 & - \\
\hline
\end{tabular}

to the Am(III) non-equilibrium distribution ratio is therefore more important.

\subsection{Counter-current test in miniature centrifugal contactor battery}

The first objective of the LUCA test was to separate Am(III) from $\mathrm{Cm}$ (III) owing to the relatively large Am(III)/Cm(III) separation factor of 6-10. The feed used for this test was an acidic feed containing trace amounts of the trivalent actinides Am(III), Cm(III) and Cf(III) (cf. Table 1). Europium was also added as a representative for the lanthanides in order to obtain information as to whether this process is also suitable for the selective extraction of Am(III) from a SANEX-type solution, leaving $\mathrm{Cm}$ (possibly also $\mathrm{Cf}$ ) in the lanthanide fraction.

The experimental conditions of the test run are described in the experimental section and the main results are summarized in Table 4. No hydrodynamic problems occurred during the test. The material balance was quite satisfactory and between $99 \%\left(\right.$ e.g. $\left.{ }^{241} \mathrm{Am}\right)$ and $112 \%\left(\right.$ e.g. $\left.{ }^{252} \mathrm{Cf}\right)$ of the elements were recovered. Yields above $100 \%$ are explainable by the sum of analytical errors $( \pm 5 \%)$ and the error of the flow rate determinations $( \pm 5 \%)$, which amounts up to $10 \%$ of material balance uncertainties. Small recovery rates, such as the yield of $0.077 \%$ of ${ }^{241} \mathrm{Am}$ in the raffinate have an error up to $20 \%$. All phases collected were clear

Table 4. Main results of the LUCA process.

\begin{tabular}{lccccc}
\hline Element & $\begin{array}{c}\% \text { in } \\
\text { raffinate } \\
(1 \mathrm{aq})\end{array}$ & $\begin{array}{c}\% \text { in } \\
\text { product } \\
(17 \mathrm{aq})\end{array}$ & $\begin{array}{c}\% \text { in } \\
\text { solvent } \\
(24 \mathrm{org})\end{array}$ & $\begin{array}{c}\mathrm{DF} \\
\text { feed/raff }\end{array}$ & $\begin{array}{c}\mathrm{DF} \\
\mathrm{Am} / \mathrm{M}(\mathrm{III})\end{array}$ \\
\hline${ }^{152} \mathrm{Eu}(\gamma)$ & 106.7 & d.1. & d.l. & 0.9 & 7693 \\
${ }^{241} \mathrm{Am}(\gamma)$ & 0.077 & 103.3 & 0.089 & 1306 & - \\
${ }^{241} \mathrm{Am}(\alpha)$ & d.1. & 98.9 & d.l. & $>1000$ & - \\
${ }^{244} \mathrm{Cm}(\alpha)$ & 108.8 & 0.469 & d.1. & 0.92 & 214 \\
${ }^{252} \mathrm{Cf}(\alpha)$ & 112.0 & 0.057 & d.l. & 0.89 & 1744 \\
Am calc'd & 0.17 & 99.8 & 0.03 & 573 & - \\
Cm calc'd & 98.7 & 1.3 & 0.0004 & - & 77 \\
\hline
\end{tabular}

d.l. $=$ below detection limit. and free of entrainment. In total, the test took $12 \mathrm{~h}(9 \mathrm{~h}$ for extraction/scrubbing and $3 \mathrm{~h}$ for stripping).

The process decontamination factors $\mathrm{DF}_{\mathrm{Am} / \mathrm{M}(\mathrm{III})}$ and $\mathrm{DF}_{\text {feed/raff }}$ were calculated according to the following Eqs. (1) and (2), where $Q$ is the flow rate in $\mathrm{mL} / \mathrm{h}$ and $C$ is the concentration of the element in $\mathrm{MBq} / \mathrm{L}$ :

$$
\begin{aligned}
& \mathrm{DF}_{\mathrm{Am} / \mathrm{M}(\mathrm{III})}=\frac{Q_{\text {feed }} C_{\mathrm{M}(\mathrm{III}) \text { feed }} C_{\mathrm{Am} \mathrm{organic} \mathrm{product} \mathrm{(stage16)}}}{Q_{\text {organic phase }} C_{\mathrm{Am} \text { feed }} C_{\mathrm{M}(\mathrm{III}) \text { organic product (stage16) }}} \\
& \mathrm{DF}_{\text {feed/raff }}=\frac{Q_{\text {feed }} C_{\text {feed }}}{Q_{\text {raff }} C_{\text {raff }}} .
\end{aligned}
$$

A high decontamination factor of over 1000 was obtained for americium between the feed and raffinate. As expected, only Am(III) was quantitatively extracted and around $99.8 \%$ Am(III) was back-extracted using $0.7 \mathrm{~mol} / \mathrm{L} \mathrm{HNO}_{3}$. A small amount of $0.09 \% \mathrm{Am}(\mathrm{III})$ remained in the spent solvent.

The raffinate contained the complete $\mathrm{Cm}$ (III) (>99.5\%), $\mathrm{Cf}(\mathrm{III})(>99.9 \%)$ and $\mathrm{Eu}(\mathrm{III})(>99.9 \%)$ inventory and the contamination of $\mathrm{Am}$ (III) $(<0.08 \%)$ was low. On the other hand, the Am(III) product after back-extraction was contaminated with only $0.47 \% \mathrm{Cm}$ (III), which resulted in a high $\mathrm{DF}_{\mathrm{Am} / \mathrm{Cm}}$ of 214. A higher decontamination factor of 1744 was measured between Am(III) and Cf(III). As expected from the high $\mathrm{Am} / \mathrm{Eu}$ separation factors obtained during the batch extraction tests, very good decontamination $\left(\mathrm{DF}_{\mathrm{Am} / \mathrm{Eu}}=7693\right)$ was achieved between $\mathrm{Am}(\mathrm{III})$ and $\mathrm{Eu}(\mathrm{III})$.

The aqueous acidity profile was in agreement with the acidities originating from the feed solutions. This is obvious as the LUCA solvent does not co-extract nitric acid.

Organic and aqueous steady-state Am(III) and $\mathrm{Cm}$ (III) concentration profiles (see Fig. 4) and effluent concentrations (see Table 4) re-calculated with the flow rates and nitric acid concentrations that were actually measured are in good agreement with the experimental results. For comparison, results from the initial calculation are: $\mathrm{Am}(\mathrm{III})$ in raffinate, $0.13 \%$; $\mathrm{Cm}$ (III) in product, $2.0 \%$; $\mathrm{Am}$ (III) in solvent, $0.03 \%$.

In the extraction section, the calculations describe the experiment very well. Only the Am(III) raffinate concentration was slightly over-estimated by the calculation $(0.17 \%$ calculated vs. $0.077 \%$ measured). The $\mathrm{Cm}$ (III) profile in the scrubbing section is described well for stages $8-13$ but 

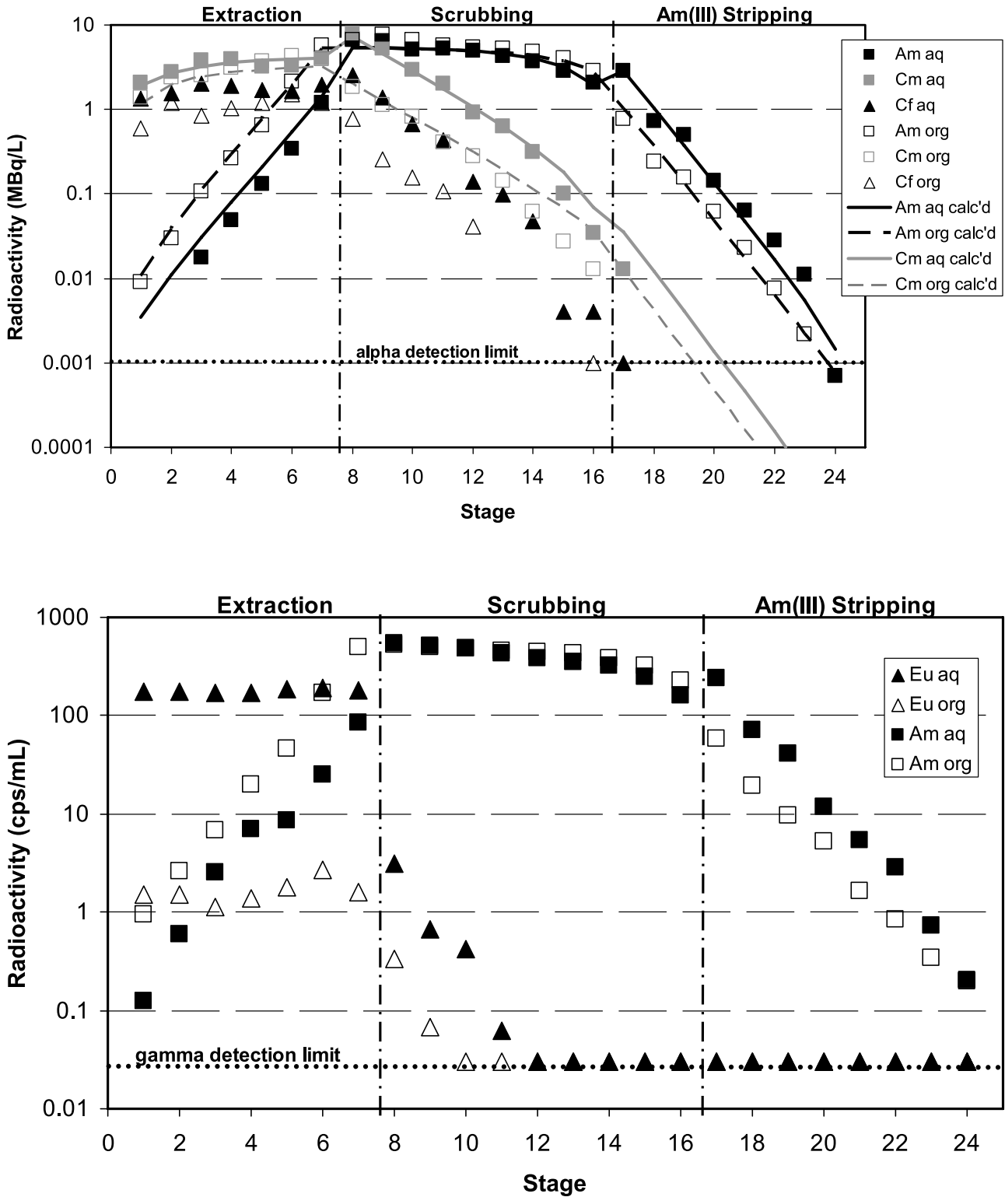

Fig. 4. Experimental (alpha measurements) and calculated steadystate concentration profiles from the counter-current test.

Fig. 5. Experimental steady-state concentration profiles of Am(III) and $\mathrm{Eu}(\mathrm{III})$ from the countercurrent test (gamma measurements).

slightly underestimated for stages $14-16$. This deviation naturally leads to an overestimation of the $\mathrm{Cm}$ (III) product concentration ( $1.3 \%$ calculated vs. $0.47 \%$ measured). The kind of calculation performed cannot predict the increasing slope of the $\mathrm{Cm}(\mathrm{III})$ profiles towards the end of the scrubbing section, as constant hydrodynamic parameters were used throughout a section. The deviation of the Am(III) concentration profiles in the first stages of the scrubbing section (stages 8-10) must be understood in the same manner. As for the stripping section, the Am(III) concentration profiles are described well; the spent-solvent Am(III) concentration was slightly underestimated $(0.03 \%$ calculated vs. $0.089 \%$ measured). No experimental data are available for $\mathrm{Cm}(\mathrm{III})$ in the stripping section. Taking into account the simplicity of the computer code used and the fact that real "predictive modelling" was performed, the results agree quite well with those of the experiment.

The concentration profiles of californium are shown also in Fig. 4. As expected, the behaviour of $\mathrm{Cf}(\mathrm{III})$ is similar to that of $\mathrm{Cm}$ (III). $\mathrm{Cf}(\mathrm{III})$ is not extracted and the scrubbing efficiently reduces the co-extraction. Only $0.045 \%$ of the initial amount was found in the Am(III) product fraction (Table 4). Fig. 5 shows the concentration profiles of Am(III) and $\mathrm{Eu}(\mathrm{III})$, which were measured by gamma spectroscopy of ${ }^{241} \mathrm{Am}$ and ${ }^{152} \mathrm{Eu}$, respectively. The extraction of $\mathrm{Eu}(\mathrm{III})$ is very low and scrubbing with $0.23 \mathrm{~mol} / \mathrm{L} \mathrm{HNO}_{3}$ decreased the concentration of Eu(III) after just 4 stages to below the detection limit. The behaviour of the other lanthanides was not studied within this test run. From our batch extraction data [23], we assume a similar behaviour for $\mathrm{Pr}, \mathrm{Nd}, \mathrm{Sm}$ and Gd. The lighter lanthanides $\mathrm{La}$ and $\mathrm{Ce}$, however, have considerably higher distribution data, although the Am/La and Am/Ce separation factors are still high (>40). Here we expect that more than 4 scrubbing stages are necessary for efficient decontamination.

\section{Conclusions}

In this paper we showed that the difficult recovery of Am(III) is possible from an acidic solution containing a mixture of trivalent actinides (Am(III), $\mathrm{Cm}$ (III) and $\mathrm{Cf}(\mathrm{III})$ ) and 
$\mathrm{Eu}(\mathrm{III})$ as a lanthanide representative. A successful LUCA demonstration was carried out in a centrifugal continuous counter-current setup using 24 stages. The main goals of the process, which were optimized by a simple computer model, were achieved: namely high recovery yields for Am(III) and good decontamination of $\mathrm{Cm}$ (III), $\mathrm{Cf}$ (III) and $\mathrm{Eu}$ (III).

The LUCA process can be used after a co-extraction process (e.g. after DIAMEX) for the selective extraction of Am(III), leaving $\mathrm{Cm}$ (III) together with the lanthanides in the raffinate fraction. Alternatively, the process can also be run after a SANEX process (e.g. BTBP) for mutual $\mathrm{Am} / \mathrm{Cm}$ separation. In the future, we plan to optimize the formulation of the extractant composition, i.e. by changing the diluent. Initial experiments showed that up to $60 \%$ of the diluent can be replaced by the aliphatic TPH [30], which is the diluent used in the La Hague reprocessing plant. The promising results obtained here with a surrogate solution should also allow a hot demonstration to be performed in the near future with a genuine process solution. We are confident, that the aromatic dithiophosphinic acids under real process conditions $(0.1-0.3 \mathrm{~mol} / \mathrm{L}$ $\mathrm{HNO}_{3}$, total doses up to $0.5 \mathrm{MGy}$ ) are sufficiently stable within the LUCA process. However, at higher acidities (> $0.5 \mathrm{~mol} / \mathrm{L} \mathrm{HNO}_{3}$, e.g. during stripping) considerable degradation (by oxidation) of the $(\mathrm{ClPh})_{2} \mathrm{PSSH}$ was observed in a former study. Oxidation of the ligand can be suppressed by adding $\mathrm{HNO}_{2}$ scavengers or using hydrochloric acid as stripping media. The results obtained represent an important breakthrough in the difficult field of actinide partitioning.

Acknowledgment. Financial support for this research was provided by the European Commission (project ACSEPT - No. 211267).

\section{References}

1. Actinide and Fission Product Partitioning and Transmutation - Status and Assessment Report. OECD-NEA, Paris, France, (1999).

2. Dinh, B., Moisy, P., Baron, P., Calor, J. N., Espinoux, D., Lorrain, B., Benchikouhne-Ranchoux, M.: Modified Purex first-cycle extraction for neptunium recovery. Proc. Internat. Solvent Extraction Conf. (ISEC 2008), Volume I (2008), pp. 581-586.

3. Nash, K. L., Madic, Ch., Mathur, J. N., Lacquement, J.: Chapt. 12, Actinide separation science and technology. In: The Chemistry of the Actinide and Transactinide Elements. $3^{\text {rd }}$ Edn. (Morss, L. R., Edelstein, N. M., Fuger, J., Katz, J. J., eds.) Springer, Dordrecht (2006).

4. Musikas, C., Vitorge, P., Pattee, D.: Progress in trivalent actinide lanthanide group separation. Proc. Internat. Solvent Extraction Conf. (ISEC '83), Denver, CO, USA, August 26-September 2 (1983).

5. Musikas, C.: Actinide-lanthanide group separation using sulfur and nitrogen donor extractants. In: Actinide/Lanthanide Separations. Proc. Int. Symp., Honolulu, HI, 16-22 December 1984 (Choppin, G. R., Navratil, J. D., Schulz, W. W., eds.) World Scientific, Singapore (1985), pp. 19-30.

6. Kolarik, Z., Müllich, U., Gassner, F.: Extraction of Am(III) and Eu(III) nitrates by 2,6-di(5,6-dipropyl-1,2,4-triazin-3-yl)pyridine. Solvent Extr. Ion Exch. 17(5), 1155-1170 (1999).

7. Geist, A., Hill, C., Modolo, G., Foreman, M. R. St. J., Weigl, M., Gompper, K., Hudson, M. J., Madic, C.: 6,6'-Bis(5,5,8,8-tetramethyl-5,6,7,8-tetrahydro-benzo[1,2,4]triazin-3-yl) [2,2']bipyridine, an effective extracting agent for the separation of americium(III) and curium(III) from the lanthanides. Solvent Extr. Ion Exch. 24, 463-483 (2006).
8. Modolo, G., Odoj, R.: Synergistic selective extraction of actinides(III) over lanthanides(III) from nitric acid using new aromatic dithiophosphinic acids and neutral organophosphorus compounds. Solvent Extr. Ion Exch. 17, 33-53 (1999).

9. Magnusson, D., Christiansen, B., Glatz, J.-P., Malmbeck, R., Modolo, G., Serrano-Purroy, D., Sorel, C.: Demonstration of minor actinide separation from a genuine PUREX raffinate by TODGA/TBP and SANEX reprocessing. Internat. Conf. ATALANTE 2008, Montpellier, France, May 19-23 (2008).

10. Pillon, S., Somers, J., Grandjean, S., Lacquement, J.: Aspects of fabrication of curium-based fuels and targets. J. Nucl. Mater. 320, 36-43 (2003).

11. Choppin, G. R., Silva, R. J.: Separation of the lanthanides by ion exchange with $\alpha$-hydroxyisobutyric acid. J. Inorg. Nucl. Chem. 3, 153-154 (1956).

12. Billon, A.: Analytical separation of americium and curium using high performance liquid chromatography. J. Radioanal. Chem. 51, 297-305 (1997).

13. Myasoedov, B. F., Guseva, L. I., Lebedev, I. A., Milyukova, M. S., Chmutova, M. K.: Analytical Chemistry of Transplutonium Elements. John Wiley, New York (1974).

14. Ikeda, A., Susuki, T., Aida, M., Otake, K., Fujii, Y., Itoh, K., Mitsugashira, T., Hara, M., Ozawa, M.: Chromatographic separation of trivalent actinides by using tertiary pyridine resin with methanolic nitric acid solutions. J. Nucl. Sci. Technol. 41(9), 915918 (2004).

15. Koyama, S., Ozawa, M., Suzuki, T., Fujii, Y.: Development of a multi-functional reprocessing process based on ion-exchange method by using tertiary pyridine-type resin. J. Nucl. Sci. Technol. 43(6), 681-689 (2006).

16. Novikov, A. P., Myasoedov, B. F.: Separation of trivalent europium, terbium, americium and curium by supported liquid membrane impregnated with di-(2-ethylhexyl)phosphoric acid. Solvent Extr. Ion Exch. 5, 117-127 (1987).

17. Myasoedov, B. F.: New methods of transplutonium element separation and determination. J. Alloys Compd. 231/214, 290-299 (1994).

18. Mason, G. W., Bollmeier, A. F., Peppard, D. F.: Partition of oxidized americium from actinides(III) and lanthanides(III). J. Inorg. Nucl. Chem. 32, 1011-1022 (1970).

19. Musikas, C., Germain, M., Bathellier, A.: Americium-curium separation by means of selective extraction of hexavalent americium using centrifugal contactor. In: Actinide Separations. (Navratil, J. D., Schulz, W. W., eds.) ACS Symp. Ser. Vol. 117, American Chemical Society, Washington, DC (1980), pp. 157-174.

20. Donnet, L., Adnet, J. M., Faure, N., Bros, P., Brossard, Ph., Josso, F.: Development of the SESAME process. $5^{\text {th }}$ Information Exchange Meeting on Actinide and Fission Product Partitioning and Transmutation, Mol, Belgium 1998, OECD-NEA, Paris, France (1999), pp. 161-168.

21. Baron, P., Lecomte, M., Boullis, B., Simon, N., Warin, D.: Separation of the long lived radionuclides: current status and future R\&D program in France. Proc. Internat. Conf. GLOBAL 2003 (Atoms for Prosperity: Updating Eisenhower's Global Vision for Nuclear Energy), New Orleans, USA, November 16-20 (2003), pp. 508-511.

22. Myasoedov, B. F., Maryutina, T. A., Litvina, M. N., Malikov, D. A., Kulyako, Yu. M., Spivakov, B. Ya., Hill, C., Adnet, J.-M., Lecomte, M., Madic, C.: Americium(III)/curium(III) separation by countercurrent chromatography using malonamide extractants. Radiochim. Acta 93, 9-15 (2005).

23. Modolo, G., Nabet, S.: Thermodynamic study on the synergistic mixture of bis(chlorophenyl)dithiophosphinic acid and tris(2ethylhexyl)phosphate for separation of actinides(III) from lanthanides(III). Solvent Extr. Ion Exch. 23, 359-373 (2005).

24. Modolo, G., Odoj, R.: Method for separating trivalent americium from trivalent curium. European patent EP 1664359B1, 3 January 2007.

25. Modolo, G, Seekamp, S.: Hydrolysis and radiation stability of the ALINA solvent for actinide(III)/lanthanide(III) separation during the partitioning of minor actinides. Solvent Extr. Ion Exch. 20(2), 195-210 (2002).

26. Geist, A., Weigl, M., Gompper, K.: Minor actinide partitioning by liquid-liquid extraction: using a synergistic mixture of 
bis(chlorophenyl)dithiophosphinic acid and TOPO in a hollow fiber module for americium(III)-lanthanides(III) separation. Sep. Sci. Technol. 37, 3369-3390 (2002).

27. Geist, A., Gompper, K.: Miniature DIAMEX processes in a hollow fibre module micro-plant: process development and optimisation. Radiochim. Acta 96, 211-218 (2008).

28. Weigl, M., Geist, A., Gompper, K.: Kinetics of Am(III)/Cm(III)/ $\mathrm{Eu}(\mathrm{III})$ extraction with a mixture of di(chlorophenyl)dithiophosphinic acid and TOPO. Proc. Internat. Conf. GLOBAL 2003 (Atoms for Prosperity: Updating Eisenhower's Global Vision for Nuclear
Energy), November 16-20, New Orleans, USA (2003), pp. 19361938.

29. Leonard, R. A., Bernstein, G. J., Pelto, R. H., Ziegler, A. A.: Liquid-liquid dispersion in turbulent Couette flow. AIChe J. 27(3), 495-503 (1981).

30. Modolo, G., Asp, H., Vijgen, H., Malmbeck, R., Magnusson, D., Sorel, C.: Demonstration of a TODGA-based continuous countercurrent extraction process for the partitioning of actinides from a simulated PUREX raffinate, part II: centrifugal contactor runs. Solvent Extr. Ion Exch. 26, 62-76 (2008). 